\title{
Effect of Educational Program of Eclampsia Management on Knowledge of Maternity Nurses at Mosul Teaching Hospitals
}

\author{
Alaa Yousif Ayed ${ }^{1}$, Radhwan Hussein Ibrahim² \\ ${ }^{1}$ Clinical Nursing Department, College of Nursing, University of Mosul, Iraq. \\ ${ }^{2}$ Clinical Nursing Department, College of Nursing, University of Ninevah, Iraq. \\ *Corresponding author. Email: yousifalaa648@uomosul.edu.iq
}

\begin{abstract}
Background: Eclampsia is a pregnancy-specific syndrome. It affects more than $5 \%$ of pregnant women and is characterized by edemas, high blood pressure and proteinuria, it considered as one of the most serious pregnancy specific medical conditions of increasing incidence. its complications are one of the top four causes of maternal deaths even in developed societies. Objective: To assess the Maternity Nurses Knowledge and educational program Regarding Eclampsia Care at Mosul Teaching Hospitals. Method and Material: A Pre-experimental study design (one group pretest-posttest) was used for period extended from 15th of November 2020 to 10th of March 2021. 30 nurses were selected by purposive sampling technique from obstetrics and gynecological departments at teaching hospitals of Mosul city. A semi-structured questionnaire was used to collect the data. Results: The results of the study showed the educational program on nurses' knowledge regarding eclampsia is effective, highly significant differences in the knowledge of nurses after implementation of the educational program compared to their knowledge before the educational program in study group. According to the findings, $53.3 \%$ of nurses had poor knowledge of prior implementation of the educational program. However, after implementation, $70.0 \%$ of them had excellent knowledge. Conclusions: The educational program has a positive effect on nurse's knowledge of eclampsia treatment, according to the study's conclusion. Recommendation: Recommendation, Continuous educational program to improve nurses' knowledge regarding care of preeclampsia and eclampsia.
\end{abstract}

Keywords: eclampsia, educational program, knowledge, nursing management.

\section{BACKGROUND}

Hypertension - or elevated blood pressure (PB) is a serious medical condition that significantly increases the risks of heart, brain, kidney, and other diseases. Hypertensive disorders of pregnancy are among the leading contributors to maternal mortality worldwide [1].

Approximately 30,000 deaths annually are attributed to hypertensive disorders including preeclampsia, eclampsia, and HELLP syndrome. Hypertensive disorder of pregnancy occurs in about $10 \%$ of all pregnant women worldwide [2] [3].

Eclampsia affects about (5-8\%) of all pregnancies, the recent report of the World Health Organization
(WHO) shows that statistics suggest 76,000 maternal mortality and morbidity annually worldwide and about 500,000 child deaths due to Preeclampsia [4] [5].

About 830 people die every day around the world from preventable causes related to pregnancy and childbirth, and an estimated 300,000 women died as a result of pregnancy-related conditions worldwide in 2015. To minimize death and morbidity, it is important to identify cases of preeclampsia, to provide efficient and effective nursing care to them. As part of the sustainable development goals, the aim between 2016 and 2030 is to reduce the global maternal mortality ratio to less than 70 per 100,000 live births [6] [7]. 
Eclampsia is pregnancy specific multisystem hypertensive disorder that is a major contributor to maternal, neonatal morbidity and mortality, eclampsia is characterized by maternal placental and vascular dysfunction in pregnant women. It is known that poor placental implantation, poor placental perfusion, and placental ischemia result in eclampsia [8] [9].

Although, the eclampsia etiology remains idiopathic and not caused by stress or overwork, but by abnormalities in the formation of blood vessels in the placenta, an organ that facilitates exchanges between the mother and the fetus. In mothers, the lack of oxygenation of the placenta may have various consequences for high blood pressure during pregnancy, kidney, liver and brain damage, as well as blood clotting disorders [10] [11].

Management of severe preeclampsia and eclampsia can be initiated by magnesium sulfate that considers the most used medication to prevent seizures as an anticonvulsant, the main goal of magnesium sulfate used for prophylaxis purpose to prevent or minimize the rate of eclampsia and eclampsia-related complications. The latest guidelines are for the administration of magnesium sulfate in patients with serious preeclampsia for seizure prophylaxis. Although magnesium sulfate is not threat-free, the key benefit of magnesium is its long safety record for mothers and children while avoiding maternal seizures [12] [13].

The only definitive "cure" for eclampsia is to deliver the fetus and placenta. The delivery decision would be based on the magnitude and degree of fetal maturity of the hypertensive disorder. The optimal timing of birth for women with pre-eclampsia depends on evolving manifestations of pre-eclampsia in one/more organ systems for the woman and baby. Steroids can be used to accelerate fetal lung maturity if the fetus is less than 34 weeks gestation, and an effort may be made to postpone birth for 48 hours [14] [15].

\section{METHOD AND MATERIALS}

Ethical approval was obtained to conduct the study from the University of Mosul/collegiate committee for medical research ethics and from Nineveh Health Department. The study's purpose and procedures were explained and emphasize the study participant's right to self-determination, confidentiality, and anonymity.

\subsection{Study Design:}

A Pre-experimental study design (one group pretestposttest) was used for period extended from 15th of November 2020 to 10th of March 2021.

\subsection{Study Setting:}

The present study was conducted at Nineveh Governorate. It is a governorate in northern Iraq, with Mosul as its capital. Mosul is Iraq's second largest city. Two governmental hospitals are included in the study (Al-Khansa Teaching Hospital and Al-Batool Teaching Hospital).

\subsection{Data Collection Period:}

The study has been conducted in a period of five months extending from 15th of November 2020 to 10th of March 2021 at Mosul Teaching Hospitals.

\subsection{Sample of the Study:}

A purposive sample was selected for the present study. A purposive sample of all nurses working at Obstetrics and Gynecological ward and operating rooms and delivery room and emergency department (30 nurses) were taken from two hospitals (Al-Batool and Al-Khansa Teaching Hospital). The sample involved (15) nurses from Al-Khansa Teaching Hospital and (15) nurses from Al-Batool Teaching Hospital.

\section{Inclusion Criteria:}

- Nurses who work in maternity departments.

- All Nurse working at two hospitals (Al-Batool Teaching Hospital and Al-Khansa Teaching Hospital).

- All Nurse volunteered to participate and provided their consent to participate in the study.

\section{Exclusion Criteria:}

- The study excluded all Nurse-midwives who are in vacations, training, sickness.

- Any nurse refused to participate in this study.

- Nurses who did not complete the program course.

- Any nurse refused to complete the post-test.

- Pilot study samples.

\section{Data Collection Tools:}

The instruments of the study were composed of (2) parts, which included the following:

1. A structured self-administered questionnaire: It was created by the researcher following a study of relevant literature a. It was divided into two sections: -

Part (I): Socio-demographic data including five points (age, years of work, level of education, workplace, workplace inside the hospital). 
Part (II): This portion was developed to assess the knowledge level of maternity nurses regarding eclampsia care and to evaluate the effectiveness of educational program Regarding Eclampsia Care at Mosul Teaching Hospitals.

\subsection{Steps of the Study:}

1. Assess needs of nurse's knowledge related to eclampsia.

2. Developed Educational program.

3. Construct questionnaire which consists to assess Knowledge of maternity nurses about eclampsia care.

4. Pre-test for the study group.

5. Implementation of the Educational program for study group.

\subsection{Scoring system of the study tool:}

The questionnaire consists of (4) domains, each domain (5) questions Knowledge scores were computed using zero ( 0 ) for the wrong answer and three (3) for the correct. The maximum score obtainable was (15) while the minimum score was (0). Scores from (0-5) show "poor knowledge," scores from (6-10) show "good knowledge" and scores from (11-15) show "excellent knowledge".

Total knowledge score was computed using zero (0) for the wrong answer and three (3) for the correct. The maximum score obtainable was (60) while the minimum score was (0). Scores from (0-20) show "poor knowledge," scores from (21-40) show "good knowledge" and scores from (41-60) show "excellent knowledge".

\subsection{Statistical Analysis:}

The Statistical Package for Social Sciences (SPSS) version 26 was used to analyze the statistical results. A descriptive approach was applied. Using percentages and frequencies to calculate nurse's demographic description characteristics. To estimate the value of the data, means and standard deviation $( \pm$ SD) were used. Pearson chi-square and t-test were used.

\section{RESULTS}

Figure 4.1 shows that is most of study participants were aged between 21-30 years old.

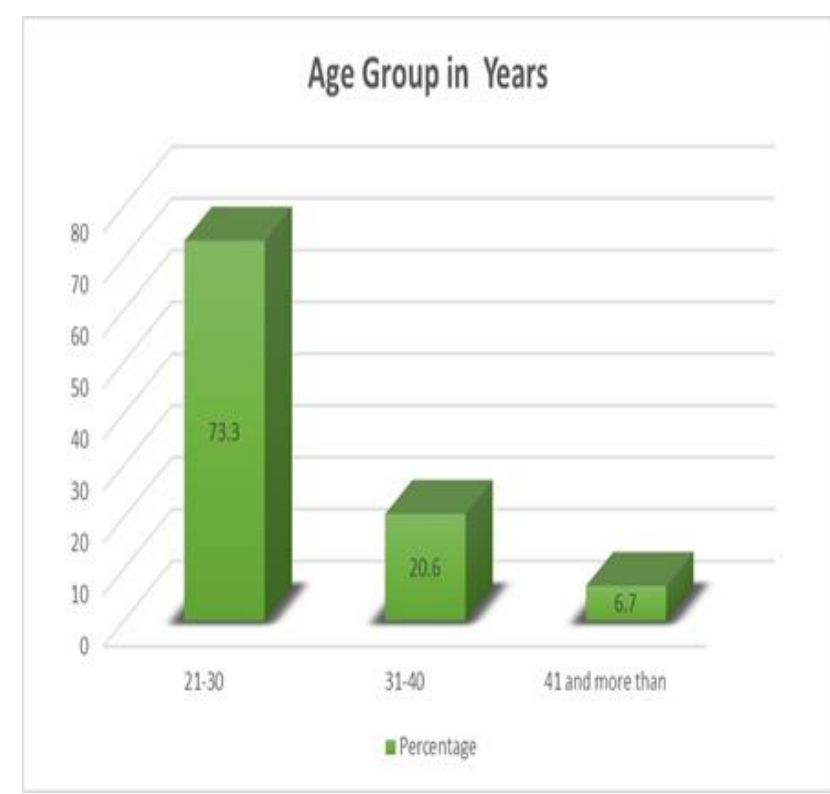

Figure 1 shows that is most of study participants were have institute educational level.

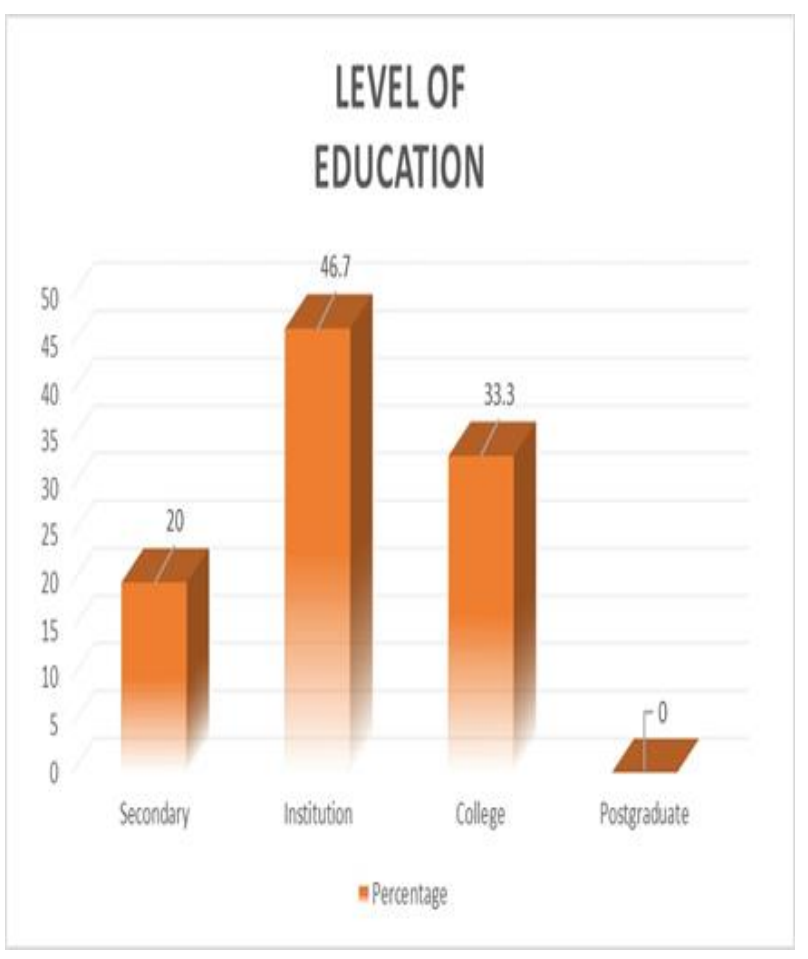

Figure 2 shows that is most of study participants have 15 years of employment. 


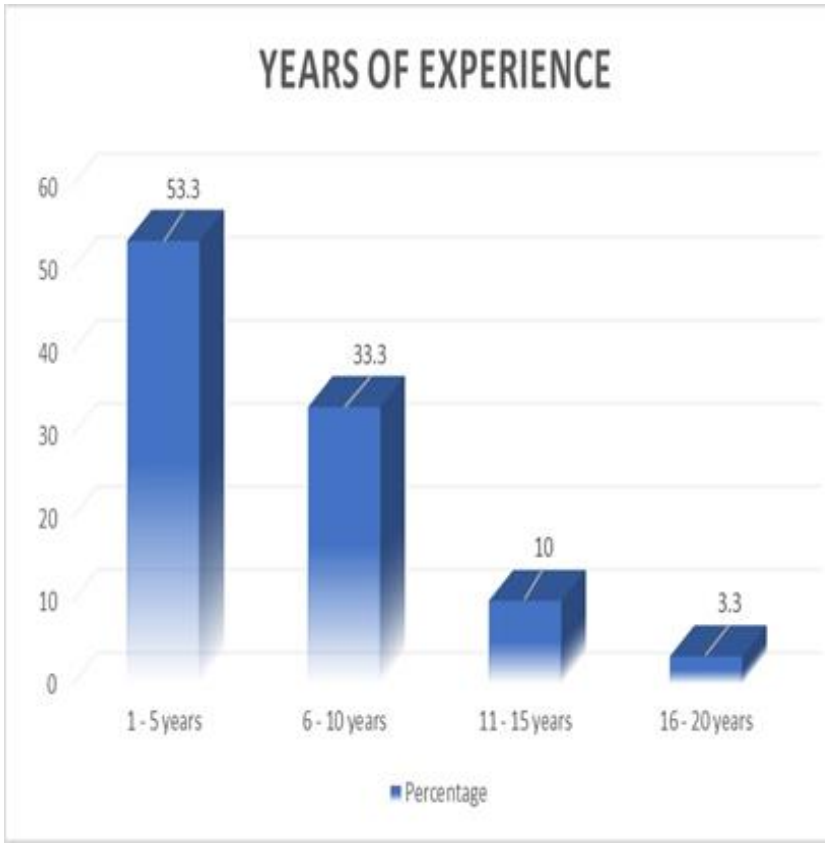

Table 1. Distribution of the maternity nurses' Demographic characteristics in the study group.

\begin{tabular}{|c|c|c|c|}
\hline \multirow{2}{*}{$\begin{array}{c}\text { The } \\
\text { Demographic } \\
\text { Variables }\end{array}$} & \multirow{2}{*}{ Items } & \multicolumn{2}{|c|}{ Study Group } \\
\hline & & F. & $\%$ \\
\hline \multirow{3}{*}{ Age(years) } & $21-30$ & 22 & 73.3 \\
\hline & $31-40$ & 6 & 20.6 \\
\hline & 41-more than & 2 & 6.7 \\
\hline \multirow{4}{*}{$\begin{array}{c}\text { Level of } \\
\text { Education }\end{array}$} & Secondary & 6 & 20.0 \\
\hline & Institution & 14 & 46.7 \\
\hline & College & 10 & 33.3 \\
\hline & Postgraduate & $\mathbf{0}$ & 00.0 \\
\hline \multirow{5}{*}{$\begin{array}{c}\text { Years of } \\
\text { experience }\end{array}$} & $1-5$ & 16 & 53.3 \\
\hline & $6-10$ & 10 & 33.3 \\
\hline & $11-15$ & 3 & 10.0 \\
\hline & $16-20$ & 1 & 3.3 \\
\hline & $21-25$ & 0 & 00.0 \\
\hline \multirow{2}{*}{$\begin{array}{c}\text { Name of the } \\
\text { Teaching hospital }\end{array}$} & Al-Kansa Hospital & 15 & 50.0 \\
\hline & Al-Batool Hospital & 15 & 50.0 \\
\hline \multirow{4}{*}{$\begin{array}{l}\text { Working } \\
\text { Place/site }\end{array}$} & Delivery room & 12 & 40.0 \\
\hline & Emergency unit & 2 & 6.7 \\
\hline & Maternity ward & 8 & 26.7 \\
\hline & Operational room & 8 & 26.7 \\
\hline \multicolumn{2}{|c|}{ Total } & 30 & 100.0 \\
\hline
\end{tabular}

Note: F: frequency; \%: percentage.

The table 1 show demographic characteristic of the study group. presents statistical relationships of the current study between the demographic variables of nurses and results of the educational program.

Table 2 Comparison between pre-test and post-test scores for study groups regarding eclampsia care (knowledge) by using Mean and SD and t-test.

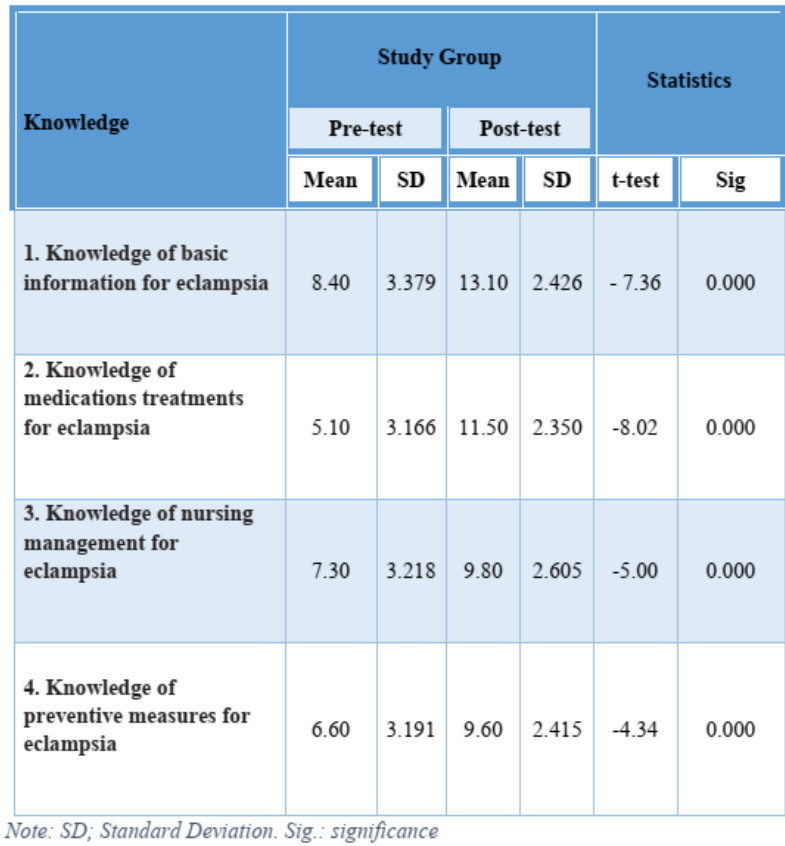

The table 2expresses the statistical total knowledge results for study in concerning care for eclampsia. which the study group at pre-test mean score for the participants was are 6.85 (SD 3.238), while in post-test mean score for the participants was are 11.0 (SD 2.449). The table shows that there is a highly significant difference in nurses' knowledge in care for eclampsia in scores regarding all topics between pre-test and post-test scores for study groups.

Table 3 Statistical Total Knowledge Results for Study group in concerning eclampsia care.

\begin{tabular}{|c|c|c|c|c|c|}
\hline \multirow{2}{*}{ Knowledge } & \multirow{2}{*}{ Estimate } & \multicolumn{2}{|c|}{ Pre-test } & \multicolumn{2}{|c|}{ Post-test } \\
\cline { 3 - 7 } & & F. & $\%$ & F. & $\%$ \\
\hline \multirow{3}{*}{1. Study Group } & Poor & 16 & 53.34 & 0 & 0.00 \\
\hline & Good & 12 & 40.0 & 9 & 30.0 \\
\hline & Excellent & 2 & 6.66 & 21 & 70.0 \\
\hline Total & & 30 & 100.0 & 30 & 100.0 \\
\hline
\end{tabular}

Note: F: frequency; \%: percentage; Poor $=(0-20)$, Good $=(21-40)$, Excellent $(41-20)$.

The table 3 expresses the statistical total knowledge results for study group in care for eclampsia. which the study group at pre-test are $53.34 \%$ (16) of them at Poor knowledge level, while in post-test are $70.0 \%$ (21) of them at Excellent knowledge level.

\section{DISCUSSION}

The table 1 shows there are no significant relationships between study group result (pre-test and post-test) with all demographic variables. High percentages (73.3\%) were of age groups (21-30) years for study. With regard to the educational level, the highest percentages $(46.7 \%)$ 
were for study groups of (Institution). These results were in agreed with results of a study which performed via [16] which confirmed that, half of the studied subjects $(50 \%)$ were in the age group ranging between 20 to less than 30 years. Concerning their educational level, the majority of the nurses (86.7\%) had nursing diploma (Institution) and supported by [17] as regarding nurses' age near half of the studied nurses $(45 \%)$ their age ranging from less than 30 years and regarding qualification, majority of nurses $(68.3 \%)$ had technical institute. This age set which is considered as young adult, so the nurses in this age group can provide nursing care efficiently and correctly.

In regard to years of work, the majority of study group were $(53.3 \%, 43.3)$ for one category $(1-5)$ years from the study group. These results supported by [18] who revealed that more than half of the nurses had experience less than 5 years $(56.7 \%)$ so the younger nurse's stay in the hospital care.

With regard to work site (inside hospital) the highest percentage $(40.0 \%)$ were working in delivery room for study groups for work site (inside hospital). These results supported by [18] and most of nurses were working in departments and delivery room. The majority work site of the whole sample was working in maternity departments. This is because the target population are in the present study the nurses who work in maternity wards, emergency units, delivery room and operational room.

The table 2 expresses the statistical total knowledge results for study in concerning care for eclampsia. which the study group at pre-test mean score for the participants was are 6.85 (SD 3.238), while in post-test mean score for the participants was are 11.0 (SD 2.449). The table shows that there is a highly significant difference in nurses' knowledge in care for eclampsia in scores regarding all topics between pre-test and post-test scores for study groups

Mohamed, et al., (2013) supported this result by reporting an improvement of nurses' knowledge in all the items of knowledge of eclampsia. These improvements were statistically significant in all the topics. This study indicates high significant differences between (pre and post-test) for study group from poor level to excellent level in post-test measurements regarding knowledge of preeclampsia care. The mean value of the knowledge of nurses regarding of $\mathrm{PIH}$ at pre-test measurement was $(1.12 \pm 0.328)$ and at post-test was $(1.80 \pm 0.404)$.

The table 3 expresses the statistical total knowledge results for study group in care for eclampsia. which the study group at pre-test are $53.34 \%$ (16) of them at Poor knowledge level, while in post-test are $70.0 \%$ (21) of them at Excellent knowledge level. Table (4.3) summarizes that most of the nurses had unsatisfactory pre-test level of knowledge about nursing care for patients undergoing eclampsia care study, while the posttest score improvement only in study group and this leads to a conclusion that the current educational program makes out to be efficacious on nurses in study sample and it is obvious through their answers in Post-test in comparison post-test for study group. This result is supported by [19] It indicates improvement of nurses' knowledge in all the items in post-test from poor to excellent. These improvements were statistically significant in all the items. Nonetheless, the levels were still significantly higher compared with pre-educational program levels.

\section{CONCLUSION}

Maternity Nurses have inadequate theoretical knowledge regarding eclampsia care before implementation of the educational program in pre-test (before program implementation). The educational program that conducted was on maternity nurses in study group is effective in improving the nurses' knowledge eclampsia care and it was evident of posttest (after program implementation).

\section{RECOMMENDATION}

Applying other educational program in all Iraqi governorate teaching hospitals. More research studies are needed to prove the efficacy of the educational programs in improving nurses' knowledge regarding eclampsia care.

\section{AUTHORS' CONTRIBUTIONS}

All authors contributed to the design, Ayed, A. Y. implement the study, and verified the analytical methods, Ibrahim , R. H. supervised the findings of this work. All authors discussed the results and contributed to the final manuscript.

\section{ACKNOWLEDGMENTS}

I would like to express my deepest thanks and gratitude to the Deanship of the College of Nursing at the University of Mosul as well as to the Branch of Clinical Nursing Sciences for their assistance and facilitation of research requirements.

\section{REFERENCE}

[1] H. R. Turbeville and J. M. Sasser, "Preeclampsia beyond pregnancy: Long-term consequences for mother and child," Am. J. Physiol. - Ren. Physiol., vol. 318, no. 6, pp. F1315-F1326, 2020, doi: 10.1152/ajprenal.00071.2020.

[2] V. D. Garovic et al., "Incidence and Long-Term Outcomes of Hypertensive Disorders of Pregnancy," J. Am. Coll. Cardiol., vol. 75, no. 18, pp. 2323-2334, 2020, doi: 10.1016/j.jacc.2020.03.028.

[3] N. Medicine, "ST AC," vol. 7058, 2018, doi: 10.1080/14767058.2018.1462323. 
[4] M. Zhang et al., "Preeclampsia among African American Pregnant Women: An Update on Prevalence, Complications, Etiology, and Biomarkers," Obstet. Gynecol. Surv., vol. 75, no. 2, pp. 111-120, 2020, doi: 10.1097/OGX.0000000000000747.

[5] H. System et al., "Estimating the Cost of Preeclampsia in the," pp. 1-8, 2017, doi: 10.1161/HYPERTENSIONAHA.117.09499.

[6] R. I. E. Hendiya, P. D. M. K. Eshra, I. K. A. Prof, and A. P. A. E. Shaheen, "Effect of Educational Program on the Knowledge of Nurses Caring for Women with Eclampsia and Pre Eclampsia," vol. 7, no. 2, pp. 577-587, 2020.

[7] K. Campbell, "Future Directions: Analyzing Health Disparities Related to Maternal Hypertensive Disorders," J. Gynecol. Womens Heal., vol. 16, no. 2, 2019, doi: 10.19080/jgwh.2019.16.555934.

[8] A. C. Staff, "The two-stage placental model of preeclampsia: An update," J. Reprod. Immunol., vol. 134-135, no. March, pp. 1-10, 2019, doi: 10.1016/j.jri.2019.07.004.

[9] Y. S. Khader, A. Batieha, R. A. Al-njadat, and S. S. Hijazi, "Preeclampsia in Jordan: incidence, risk factors, and its associated maternal and neonatal outcomes," J. Matern. Neonatal Med., vol. 31, no. 6, pp. 770-776, 2018, doi: 10.1080/14767058.2017.1297411.

[10] H. Haque and K. Thapa, "Maternal and Fetal Outcome in Eclampsia: A Study From Tertiary Care Hospital," vol. 15, no. 2, pp. 6-9, 2017.

[11] B. M. Sibai, "Etiology and management of postpartum hypertension-preeclampsia," YMOB, vol. 206, no. 6, pp. 470-475, 2012, doi: 10.1016/j.ajog.2011.09.002

[12] A. Malik, B. Jee, and S. Kumar, "Preeclampsia : Disease biology and burden, its management strategies with reference to India," Pregnancy Hypertens., vol. 15, no. October 2018, pp. 23-31, 2019, doi: 10.1016/j.preghy.2018.10.011.

[13] T. X. da Costa, F. J. Azeredo, M. A. G. Ururahy, M. A. da Silva Filho, R. R. Martins, and A. G. Oliveira, "Population Pharmacokinetics of Magnesium Sulfate in Preeclampsia and Associated Factors," Drugs R D, vol. 20, no. 3, pp. 257-266, 2020, doi: 10.1007/s40268-020-00315-2.

[14] S. Chandrasekaran and R. Simon, "Hepatic Complications in Preeclampsia," Clin. Obstet. Gynecol., vol. 63, no. 1, pp. 165-174, 2020, doi: 10.1097/GRF.0000000000000501.

[15] A. Williams, A. Khan, M. Moniruzzaman, and T. Rahaman, "Management of Preeclampsia, Severe Preeclampsia ," vol. 7, no. 3, pp. 457-468, 2019.
[16] M. A. El-bahy, H. I. Mohamed, N. S. Salam, and E. H. Nasr, "Effect of Educational Program for Nurses about Pregnancy Induced Hypertension on their Knowledge in Port Said Hospitals," Med. J. Cairo Univ., vol. 81, no. 2, pp. 179-188, 2013.

[17] E. El Rheem Emam and N. Mousa Saber, "Effect of Nursing Program on Improving Nurses' Knowledge and Skills Regarding Care of Eclamptic Women," Am. J. Nurs. Res., vol. 6, no. 6, pp. 430-436, 2018, doi: 10.12691/ajnr-6-6-10.

[18] Safaa S. Ahmed; Hanaa K. Helmy; Amel A. Mohamed, "Impact of a tailored Intensive Educational Program upon Preeclampsia on Nurses'Knowledge at Beni-Suef City, Egypt.,' Int. J. Nurs. Sci., vol. 7, no. 4, pp. 79-83, 2017, doi: 10.5923/j.nursing.20170704.01.

[19] S. T. Kadhim and S. H. Khairi, "Effectiveness of Educational Program on Nurse-midwives' Knowledge about Pregnancy Induced Hypertension at Bint Al-Huda Hospital in Al-Nasiriya City," Indian J. Forensic Med. Toxicol., vol. 14, no. 3, pp. 2714-2719, 2020, doi: 10.37506/ijfmt.v14i3.10849. 